D. O'B. Hourihane ${ }^{16}$ has reviewed all the cases recorded as primary diffuse tumours of the pleura or peritoneum in the necropsy files of the London Hospital between 1917 and 1962 irrespective of exposure to asbestos. He accepted as mesotheliomata 17 out of 38 pleural tumours and 17 out of 55 peritoneal tumours with characteristics which clearly distinguished them from primary carcinomata of the lung or other viscera.

There appears to be no correlation between the degree of severity of asbestosis and the occurrence of pleural or peritoneal tumours, and in some cases the exposure to asbestos dust seems to have been slight. Information is being collected $^{17}$ to determine what proportion of these uncommon tumours occur in people who have been exposed at some time to asbestos dust. W. T. E. McCaughey and his colleagues, ${ }^{18}$ reviewing 15 patients with mesothelioma of the pleura, found asbestos bodies in the lung in 12, most of whom were likely to have had some industrial exposure to asbestos. Asbestos bodies should certainly be looked for in the lungs of patients with mesotheliomata. However, it is difficult to assess the significance of this finding as long as the incidence of asbestos bodies in lungs without accompanying mesotheliomata is unknown. Hourihane found a significant incidence of asbestos bodies and fibres in the lung in his cases with mesotheliomata compared with consecutive necropsy cases of carcinoma of the lung and consecutive cases without a tumour in the chest.

On what does the probable carcinogenic action of asbestos depend ? The members of the series of fibrous silicates to which the term asbestos is applied have different physical properties and chemical compositions. Chrysotile is a magnesium silicate with long, strong fibres suitable for spinning. Crocidolite and amosite are iron-containing silicates with shorter fibres. Many of the tumours reported so far have been associated with crocidolite, and some with chrysotile. If only certain varieties of asbestos are found to be associated with malignant disease a valuable clue might be provided. It has been suggested that because of its physical properties the asbestos fibre gives rise to chronic irritation and eventually to malignant change. J. S. Harington ${ }^{19}$ extracted from crocidolite, and to a lesser extent from amosite, small amounts of fluorescent oils containing 3:4 benzpyrene and other polycyclic aromatic hydrocarbons which he thought had been produced by the primitive organisms present when the asbestos-containing rock system was deposited. The possible role of iron in the carcinogenic action of asbestos is also being investigated. Little experimental work on the carcinogenic effects of asbestos has been published. Wagner ${ }^{20}$ obtained three mesotheliomata in 50 rats injected intrapleurally with asbestos, but he also obtained one similar tumour in a group of ten injected in the same way with silica.

There are many uses for the $2 \frac{1}{2}$ million tons of asbestos now being produced annually, and though the number of certified cases of asbestosis is decreasing more people may be inhaling a smaller concentration of the fibres, not only in industry but possibly also as a result of the contamination of the environment. If only certain varieties of asbestos are carcinogenic others could be substituted for them. Until we know the answers to some of the questions posed by the recent findings all exposure to asbestos dust should be considered as hazardous, and supervision should be extended to insulation workers in ships, factories, and domestic buildings who may be intermittently but nevertheless heavily exposed to asbestos dust.

\section{Computers in Medicine}

It is often said that medicine is applied biology. But until recently the idea that medicine might also become an important focusing point for mathematics and computer science would have seemed strange to most people. A recent leading article in these columns on automation in hospitals called attention to the fact that a time for revaluations is at hand. ${ }^{1}$ New methods are claiming a place in the traditional framework of medical research and practice.

Nothing could have given sharper emphasis to this than the conference held in Oxford a fortnight ago on Mathematics and Computer Science in Biology and Medicine, organized jointly by the Medical Research Council and the Ministry of Health. . The topics ranged from the latest methods developed in America for computer-aided processing of hospital records to the abstract logical and mathematical problems underlying automatic classification, whether of diseases for diagnostic purposes, of organisms for taxonomy, or of documents in systems of information retrieval. A series of distinguished speakers strove cheerfully, and on the whole successfully, to communicate at least in outline the mathematics involved in the analysis of electroencephalograms and electrocardiograms, in devising and testing models of epidemiological processes, and in interpreting changes of state in living tissues.

There are few in biology and medicine to-day who do not recognize that the new methods have come to stay and that the medical man must learn both to live with them and to exploit them for his own use. Yet most of us watch the advance of the computer with some apprehension. There is in addition a widespread belief that in order to use a computer effectively one must, first, be very clever and, secondly, have mathematics at one's finger-tips. Though perhaps valid in the early days of computers, these beliefs and apprehensions are now increasingly based on fallacy. In this context two contributions to the Oxford conference may be picked out as opening doors to the use of computers as sophisticated research tools without the need for any special training on the part of the user beyond the capacity to think clearly.

R. S. Ledley, of the National Biomedical Research Foundation, Maryland, U.S.A., described to the Conference a system for using the computer in the scanning and interpretation of photomicrographs of human chromosome preparations. The system has several man-years of highly specialized programming effort behind it. But now that the work has been done any cytologist may use the system or even modify and extend it by employing methods which can be learnt in an hour or so.

A further stage in the "spoon-feeding" of the user by the machine was illustrated in a dramatic demonstration by $M$. V. Wilkes, director of the Mathematical Laboratory, Cambridge University. From a lecture hall in Oxford he communicated with an IBM 7094 computer in the Massachusetts Institute of Technology using G.P.O. Telex equipment. By typing an appropriate message into the teleprinter he activated a programme in the M.I.T. programme library which printed out its own operating instructions, interrogating and guiding the user at every step. A member of the audience was thus able to execute a complicated mathematical task without having to use anything beyond plain English. A further feature oi the M.I.T. installation, remarkable by British standards, is that dozens of users can plug in to the same 
machine in parallel, none interfering with each other's work nor wasting a millisecond of machine time.

That it is entirely possible to make intricate formal systems comprehensible to the uninitiated was shown in dazzling style by Francis Crick, Nobel Prize winner, whose evening discourse on "The Genetic Code" was a great event. His example could scarcely fail to inspire renewed efforts to overcome the barriers of communication dividing the different trades and disciplines represented at the Conference. It may sometimes seem that the divergences of outlook, tradition, and temperament between, say, the computer scientist and the clinician are so great that the problem of allying the former's skills to the clinician's practice is beyond solution. Certainly the problem will have to be faced explicitly soon. In the meantime we should do well to keep in mind the words of Sir Harold Himsworth in his opening address to the Conference: "We must learn each other's language and understand each other's point of view. This is not a co-operation that can be carried on by post. The biologist and medical man have much to learn from the mathematicians and the computer scientists. But equally they have much to learn from medicals and biologists. Neither is in a position to presume what is good for the other."

\section{Sick-pay for Workers}

Both political parties are understood to be reviewing the social security schemes introduced after the war. One that might well undergo revision is the sickness benefit payable under national insurance, which costs about $£ 185 \mathrm{~m}$. a year. It has been suggested that as so many workers are now covered ty industrial or occupational sick-pay schemes these should be made compulsory in all firms over a certain size. The national scheme would then be restricted in scope to, for instance, the self-employed, employees of small firms, and the long-term sick who had exhausted their right to sick pay. Benefits under it could then be much higher than the present standard rate of $67 \mathrm{~s}$. $6 \mathrm{~d}$. a week plus dependants' allowances.

An important start in providing the factual information needed before a revision of this sort could take place has now been made. The Ministry of Pensions and National Insurance has undertaken an inquiry into "the nature and extent of incapacity for work in different occupations and in different areas" in the year ended 2 June 1962. The results of this inquiry will be published later in the year, but in the meantime the Ministry has published a considerable amount of information on sick-pay schemes, which it collected incidentally to the main inquiry. ${ }^{1}$ From a sample of $5 \%$ of men and $2 \frac{1}{2} \%$ of women insured for national insurance sickness benefit it found that $57 \%$ of the men, $52 \%$ of the married women, and $62 \%$ of the single women were covered by some sort of sick-pay scheme. (The sample of married women was not representative of all married women in the working population because a high proportion of them elect not to be insured under the national scheme.) Broken down by industry and occupation the analysis showed that the proportion of people covered is highest in the public services, nationalized industries, and the professions, and lowest in unskilled jobs.

Report of an Inquiry into the Incidence of Incapacity for Work, Pt. I H.M.S.O., 1964 11s. 6d. net.
The Ministry then went on to find out from a sub-sample what the broad provisions of these schemes are. About six out of ten of the men and about half the women have to have served a certain period in the job before qualifying for sick pay, the periods most common being a year or six months. But a waiting period such as exists under national insurance is not common. Once qualified for sick pay, seven out of ten of the men and nearly nine out of ten of the women are entitled to it from the first day of sickness. There are considerable differences, however, in the duration of sick pay. About a quarter of men and women are said to be entitled to it at their employer's discretion; but it seems that $12 \%$ of men are eligible for a year's pay or more and 30\% for at least three months. Most of them, too, are paid full wages (seven out of ten men and nine out of ten women), at least at the start of their illness, but "full wages" usually meant that national insurance benefit was deducted. Combining the information obtained from the sub-sample with that from the main sample the Ministry estimated that four out of ten of the men and just over half the women would receive full wages (usually less national insurance benefit) from the first day of their illness, once they had qualified for their sickpay scheme.

It would be interesting, especially to doctors, to know whether sick-pay schemes encourage people to take sick leave more readily. On this the Ministry's report is noncommittal. It does appear that workers covered by such schemes are more likely than others to go sick. On the other hand, a worker's average number of days of incapacity in a year for all occupations is the same (nine) for those with sick pay as for those without-though heavy workers like miners had more days cff if they had sick-pay than if they had not. As the Ministry says, "There are important factors governing the extent of incapacity for work other than the provision of sick-pay schemes." It also suggests that in some cases sick-pay, by encouraging people to stay away from work at the beginning of their illness, may shorten the duration of incapacity. Clerical workers without sick-pay, for instance, had fewer absences than their fellows with it, but their average number of days off from sickness was greater. In its simplest form it is the question of whether a couple of days off at the start of a cold prevents bronchitis.

\section{Carcinogen in Groundnuts}

Since the recognition of aflatoxin in $1960^{1}$ much has been learned about its nature and distribution. It is a metabolite of certain strains of Aspergillus flavus, a fungus commonly found in groundnuts. It penetrates the kernel when the shell is damaged during harvesting. If the groundnuts are not adequately dried immediately after harvesting the fungus may grow rapidly. The toxin is very stable, so that though the fungus is killed during processing of the nuts the toxin is unaltered. Toxin-producing strains of the fungus have also been isolated from cotton seed ${ }^{2}$ and will grow on grain and artificial media. Two main components of aflatoxin-namely, $B_{1}$ and $G_{1}$-have been isolated ${ }^{3}$ and their structure has been worked out by a group under G. Buchi ${ }^{4}$ at the Massachusetts Institute of Technology. 